\title{
Influence of the Secondary Structure of PPAs in the Formation of Silver Nanoparticles ${ }^{\dagger}$
}

\author{
Manuel Núñez-Martínez, Emilio Quiñoá and Félix Freire* \\ Centro Singular de Investigación en Química Biolóxica e Materiais Moleculares (CiQUS), Universidade de \\ Santiago de Compostela, 15705 Santiago de Compostela, Spain; manuelnunez.martinez@usc.com (M.N.-M.); \\ * Correspondence: felix.freire@usc.es \\ + Presented at the 24th International Electronic Conference on Synthetic Organic Chemistry, 15 November- \\ 15 December 2020; Available online: https://ecsoc-24.sciforum.net/.
}

Received: date

\begin{abstract}
In the last years, the preparation of novel nanocomposites based on polymers and metal nanoparticles (AuNPs and AgNPs) has attracted the attention of the scientific community. This is due to their potential applications in fields such as sensing, medical therapy or catalysis, among others. In literature, several examples for the preparation of nanocomposites can be found where the organic coating is composed by biomacromolecules with helical structure such as DNA or proteins but nanocomposites with synthetic helical polymers as coating still remain unexplored. For this reason, poly(phenylacetylene)s (PPAs), which are a type of synthetic helical polymers, are excellent candidates to act as organic coatings for metal nanoparticles. PPAs present the ability of modulating its secondary structure-helical sense and elongation-in the presence of different external stimuli (e.g., temperature, metal ions, light, etc.). In this work, the preparation of novel nanocomposites based on PPA-AgNPs is reported. For that purpose, meta- and orto- substituted PPAs derived from $(R)-\alpha$-methoxy- $\alpha$-phenylacetic acid as pendant groups (poly-1 and poly- 2 respectively) were selected as organic coating for the silver nanoparticles. The differences in the elongation and dynamic behaviour between poly-1 and poly-2 allowed us to study the influence of the secondary structure in the formation of poly-1-AgNPs and poly-2-AgNPs nanocomposites.
\end{abstract}

Keywords: poly(phenylacetylene)s; silver nanoparticles; helical polymers

\section{Introduction}

The development of new nanomaterials has obtained a great relevance in the scientific community due to its applications in fields such as sensing [1], theranostic [2], catalysis [3], among others. Several works explored the preparation of gold and silver nanoparticles (AuNPs, AgNPs) with biomacromolecules (DNA or proteins) as organic coating. In these works, the chirality of the nanocomposites is fixed by the helical structure of the biomacromolecules.

Interestingly, the preparation of AuNPs and/or AgNPs using synthetic helical polymers still remains unexpolored [4,5]. Poly(phenylacetylene)s [6,7] (PPAs) are a family of synthetic dynamic helical polymers where the helical sense and/or elongation can be tuned by the addition of external stimuli such as temperature, metal ions, $\mathrm{pH}$, polarity of solvents, etc. [8-14] These properties convert PPAs in excellent candidates to form novel nanocomposites with chiral modulable surface.

In this work, we report the preparation of new nanocomposites based on PPAs bearing the 3and 2-anilide of $(R)-\alpha$-methoxy- $\alpha$-phenylacetic acid (poly-1 and poly-2 respectively) and AgNPs (poly-1-AgNPs and poly-2-AgNP). Previous studies have demonstrated that the aromatic substitution pattern in PPAs affects the dynamic behavior and elongantion of the helical polymers. Thus, poly-1 showed the ability to respond to the addition of metal ions and the combination of two types of helices. The first one corresponds to a compressd (cis-cisoidal) helix and the second one is a 
more stretched (cis-transoidal) helix. In the case of poly-2, the PPA did not show the ability to respond to the presence of metal ions and structural studies showed that poly-2 presents the most stretched structure with an almost planar structure [13]. For these reasons, the study of the influence of the secondary structures of poly-1 and poly-2 is a very important factor to develop novel nanocomposites.

\section{Materials and Methods}

The preparation and characterization of poly-1 and poly-2 can be found in [13,14].

$\mathrm{CD}$ measurements were carried out in a Jasco-720 and the concentration of the nanocomposite was $0.3 \mathrm{mg} \mathrm{mL}^{-1}$. UV-Vis studies were done in a Jasco V-630 and the concentration of nanocomposite was $0.3 \mathrm{mg} \mathrm{mL}^{-1}$.

GPC studies were carried out in a Waters Alliance equipped with Phenomenex GPC columns. The concentration of polymer was $0.5 \mathrm{mg} \mathrm{mL}^{-1}$ in THF. SEM measurements were carried out in a LEO 435-VP electron microscope equipped with an energy dispersive $\mathrm{X}$ ray (EDX) detector. A drop of the selected polymer $(0.3 \mathrm{mg} \mathrm{mL}-1)$ was settled on a silicon wafer chip. DLS measurements were performed on a Nano-ZS 90 (Malvern) equipped with a He-Ne laser $(1=633 \mathrm{~nm})$ under scattering angle of $173^{\circ}$. The samples were maintained at the designed temperature for $5 \mathrm{~min}$ before testing. TEM measurements were performed on a JEOL JEM 2010 and $200 \mathrm{KV}$ as a voltage. The samples $(0.03 \mathrm{mg}$ $\mathrm{mL}^{-1}$ ) were drop casted onto a carbon grid.

\section{Results and Discussion}

A direct chemical reduction is employed to prepare poly-1-AgNPs and poly-2-AgNPs nanocomposites. In a first step, the metal nanoparticles precursor $\left(\mathrm{AgClO}_{4}\right)$ is added to a solution of the PPA to form PPA/ $\mathrm{Ag}^{+}$complexes. Finally, $\mathrm{NaBH}_{4}$ is added as reducing agent to form PPA-AgNPs nanocomposites. The preparation of poly-1-AgNPs and poly-2-AgNPs nanocomposites will allow determining the influence of the backbone of the PPA in the size, shape and stability of AgNPs.

\subsection{Preparation of Poly-1-AgNPs Nanocomposites}

Poly-1 presents an interesting helical structure where two types of helices (compressed and stretched) are present. Moreover, poly-1 presents a little dynamic behavior in presence of metal ions such as $\mathrm{Li}^{+}, \mathrm{Ag}^{+}$, etc., protocol described above were employed to prepare poly-1-AgNPs. For that purpose, 0.5 equiv. of $\mathrm{AgClO}_{4}\left(10 \mathrm{mg} \mathrm{mL}^{-1}, \mathrm{MeOH}\right)$ was added to chloroform solution of poly-1 $(0.3 \mathrm{mg}$ $\left.\mathrm{mL}^{-1}\right)$ to form poly-1/Ag+ complexes. Next, 1 equiv. of $\mathrm{NaBH}_{4}\left(1 \mathrm{mg} \mathrm{mL}{ }^{-1}, \mathrm{MeOH}\right)$ was added to form poly-1-AgNPs nanocomposites.

Interestingly, poly-1-AgNPs showed an active CD in the vinylic region $(380 \mathrm{~nm})$ indicating that nanocomposites preserve the helical structure present in poly-1 and the AgNPs do not disturb the secondary structure of poly-1. Moreover, the UV-Vis studies of the resulting nanocomposites showed the presence of a typical Localized Surface Plasmon Resonance band at $410 \mathrm{~nm}$ for spherical AgNPs. The morphology and size of the AgNPs in the nanocomposite was confirmed by electronic transmission microcopy. The microscopy images showed the formation of polydisperse spherical AgNPs. Unfortunately, the AgNPs obtained presented a poor stability in solution and the aggregation was observed a few hours. 
a)

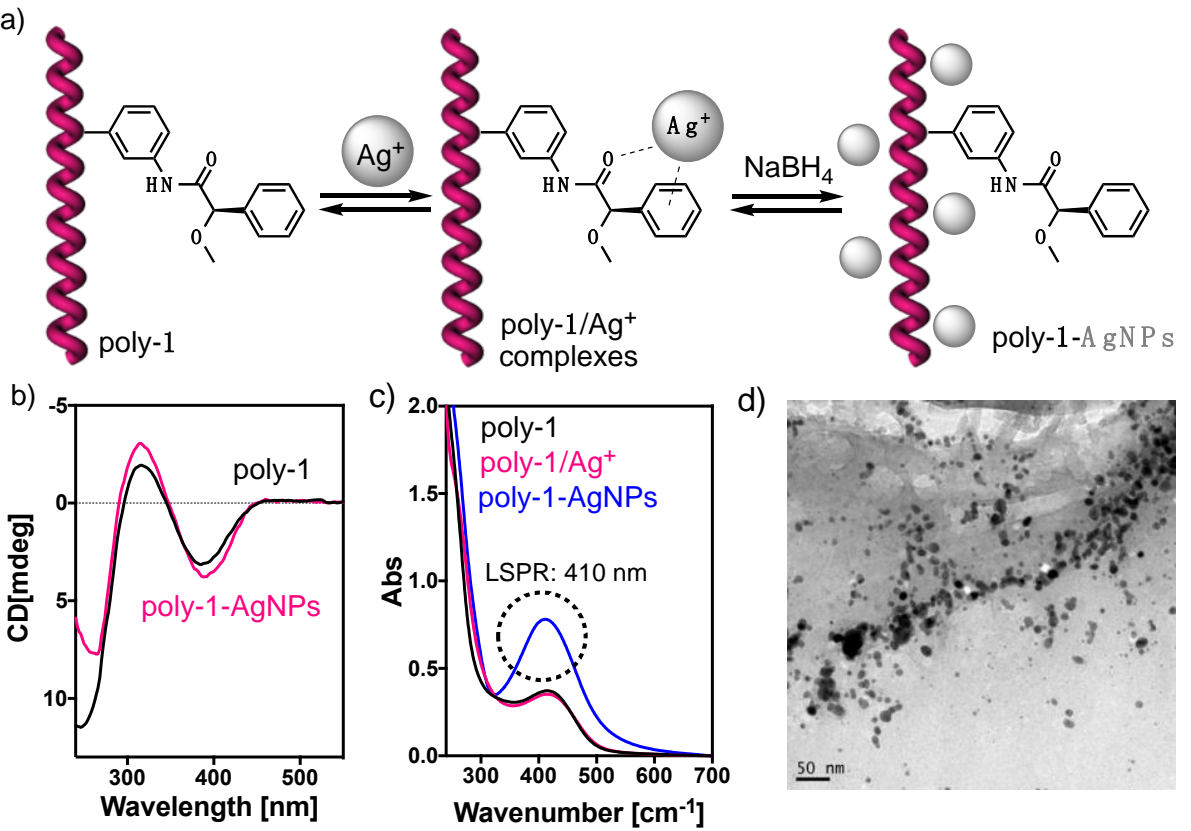

Figure 1. (a) Schematic representation for the formation of poly-1-AgNPs through direct chemical reduction. (b) CD traces for poly-1 and poly-1-AgNPs. (c) UV-Vis traces for poly-1, poly-1/Ag ${ }^{+}$and poly-1-AgNPs. (d) TEM image for poly-1-AgNPs.

\subsection{Preparation of Poly-2-AgNPs Nanocomposites}

Poly-2 present a totally different structure compared to poly-1. This PPA shows the most stretched structure and does not respond to the addition of metal ions indicating a static behavior. nanocomposites was employed the same protocol that in the case of poly-1-AgNPs was employed to prepare poly-2-AgNPs.

For that purpose, 0.5 equiv. of $\mathrm{AgClO}_{4}\left(10 \mathrm{mg} \mathrm{mL}^{-1}, \mathrm{MeOH}\right)$ was added to a solution of poly-2 $\left(0.3 \mathrm{mg} \mathrm{mL}-1, \mathrm{CHCl}_{3}\right)$ to form poly-2/ $\mathrm{Ag}^{+}$complexes. Because of the static behavior of poly-2, the addition of $\mathrm{Ag}^{+}$ions does not promote any changes in the $\mathrm{CD}$ traces of poly-2/Ag+. Finally, 1 equiv. of $\mathrm{NaBH}_{4}\left(1 \mathrm{mg} \mathrm{mL}^{-1}, \mathrm{MeOH}\right)$ was added to form poly-2-AgNPs nanocomposites. Interestingly, the $\mathrm{CD}$ traces for poly-2-AgNPs preserved the same Cotton Effect at $380 \mathrm{~nm}$ and the same intensity compared to the parent polymer (poly-2) because the AgNPs do not affect to the secondary structure of poly-2. The UV-Vis studies for poly-2-AgNPs confirmed the formation of spherical AgNPs due to the presence of LSPR band at $410 \mathrm{~nm}$. Interestingly, TEM images for poly-2-AgNPs showed the formation of longitudinal AgNPs probably due to the aggregation of spherical AgNPs during the drop casting process onto the carbon grid for TEM. 
a)

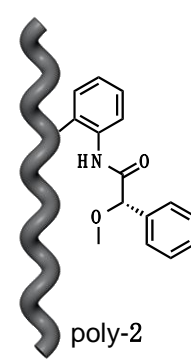

b)

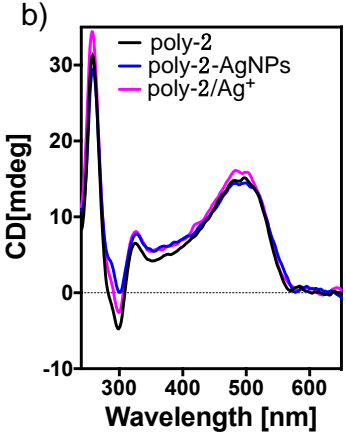

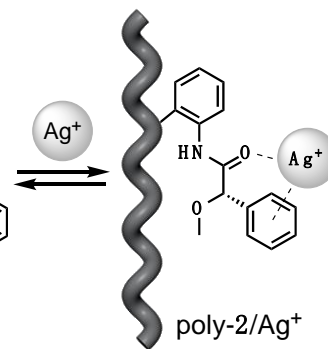
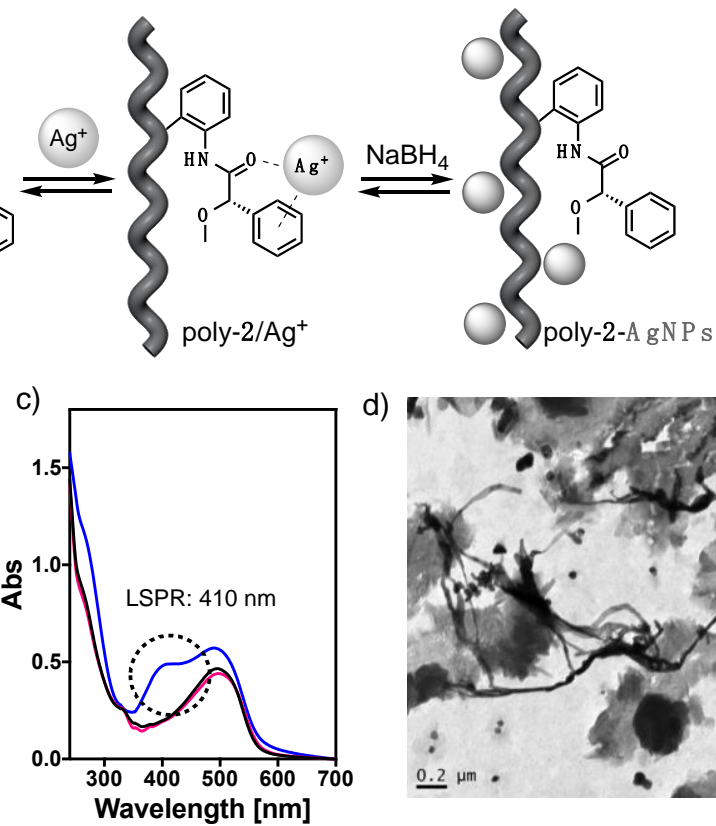

Figure 2. (a) Schematic representation for the formation of poly-2-AgNPs through direct chemical reduction protocol. (b) CD traces for poly-2, poly-2 in presence of $\mathrm{Ag}^{+}$ions and poly-1-AgNPs. (c) UVVis traces for poly-2, poly-2/Ag ${ }^{+}$and poly-2-AgNPs. (d) TEM image for poly-2-AgNPs.

\section{Conclusions}

In this work, the important role of the secondary structure of PPAs for the formation of PPAAgNPs was demonstrated. For that purpose, two PPAs with different substitution aromatic pattern (poly-1 and poly-2) were employed to prepare the nanocomposites. In the case of the nanocomposites derived from the 3-anilide of $(R)-\alpha$-methoxy- $\alpha$-phenylacetic acid (poly-1-AgNPs), the formation of polydisperse and poor stable AgNPs was observed probably due to the weak protection ability of poly-1 to stabilize AgNPs. In the case of the nanocomposites derived from the 2-anilide of $(R)-\alpha$ methoxy- $\alpha$-phenylacetic acid (poly-2-AgNPs), the TEM images showed the formation of longitudinal silver aggregates. The stretched structure, almost planar, and the weak protection ability of poly- $\mathbf{2}$ is responsible for the formation of this type of nanostructures.

\section{Patents}

This section is not mandatory, but may be added if there are patents resulting from the work reported in this manuscript.

Acknowledgments: We thank Servicio de Microscopía Electrónica (RIAIDT, USC). Financial support from MINECO (CTQ2015-70519-P), Xunta de Galicia (ED431C 2018/30, Centro singular de investigación de Galicia accreditation 2016-2019, ED431G/09) and the European Regional Development Fund (ERDF) is gratefully acknowledged. M. N.-M. Thanks MICINN for a FPI contract.

Conflicts of Interest: The authors declare no conflict of interest.

\section{References}

1. Zhang, S.; Geryak, R.; Geldmeier, J.; Kim, S.; Tsukruk, V. Synthesis, Assembly, and Applications of Hybrid Nanostructures for Biosensing. Chem. Rev. 2017, 117, 12942-13038.

2. Molina, M.; Asadian-Birjand, M.; Balach, J.; Bergueiro, J.; Miceli, E.; Calderon, M. Stimuli-Responsive nanogel composites and their applications in nanomedicine. Chem. Soc. Rev. 2015, 17, 6161-6186.

3. Zhou, Y.; Sun, H.; Matysiak, S.; Ren, J.; Qu, X. Mesoporous Encapsulated Chiral Nanogold for Use in Enantioselective Reactions. Angew. Chem. Int. Ed. 2018, 57, 16791-16795. 
4. Bergueiro, J.; Núñez-Martínez, M.; Arias, S.; Quiñoá, E.; Riguera, R.; Freire, F. Chiral Gold-PPA Nanocomposites with Tunable Helical Sense and Morphology. Nanoscale Horiz. 2020, 5, 495-500.

5. Zhang, C.; Song, C.; Yang, W.; Deng, J. Au@poly(N-propargylamide) Nanoparticles: Preparation and Chiral Recognition. Macromol. Rapid Commun. 2013, 34, 1319-1324.

6. Yashima, E.; Maeda, K.; Furusho, Y. Single- and Double-Stranded Helical Polymers: Synthesis, Structures, and Functions. Acc. Chem. Res. 2008, 41, 1166-1180.

7. Yashima, E.; Maeda, K.; Lida, H.; Furusho, Y.; Nagai, K. Helical Polymers: Synthesis, Structures, and Functions. Chem. Rev. 2009, 109, 6102-6211.

8. Freire, F.; Quiñoá, E.; Riguera, R. Supramolecular Assemblies from Poly(phenylacetylene)s. Chem. Rev. 2016, 116, 1242-1271.

9. Freire, F.; Seco, J.M.; Quiñoá, E.; Riguera, R. Helical Polymer-Metal Complexes: The Role of Metal Ions on the Helicity and the Supramolecular Architecture of Poly(phenylacetylene)s. Adv. Polym. Sci. 2013, 262, 123-140.

10. Arias, S.; Freire, F.; Quiñoá, E.; Riguera, R. The leading role of cation- $\pi$ interactions in polymer chemistry: The control of the helical sense in solution. Polym. Chem. 2015, 6, 4725-4733.

11. Arias, S.; Núñez-Martinez, M.; Quiñoá, E.; Riguera, R.; Freire, F. A general route to chiral nanostructures from helical polymers: P/M switch via dynamic metal coordination. Polym. Chem. 2017, 8, 3740-3745.

12. Suárez-Picado, E.; Quiñoá, E.; Riguera, R.; Freire, F. Poly(phenylacetylene) Amines: A General Route to Water-Soluble Helical Polyamines. Chem. Mater. 2018, 30, 6908-6914.

13. Rodríguez, R.; Quiñoá, E.; Riguera, R.; Freire, F. Architecture of Chiral Poly(phenyl acetylene)s: From Compressed/Highly Dynamic to Stretched/Quasi-Static Helices. J. Am. Chem. Soc. 2016, 138, 9260-9268.

14. Freire, F.; Seco, J.M.; Quiñoá, E.; Riguera, R. Nanospheres with Tunable Size and Chirality from Helical Polymer-Metal Complexes. J. Am. Chem. Soc. 2012, 134, 19374-19383.

Publisher's Note: MDPI stays neutral with regard to jurisdictional claims in published maps and institutional affiliations.

(C) 2020 by the authors. Submitted for possible open access publication under the terms and conditions of the Creative Commons Attribution (CC BY) license (http://creativecommons.org/licenses/by/4.0/). 